\title{
An Efficient and Optimized PCR Method with High Fidelity for Site-directed Mutagenesis
}

\author{
Qianwa Liang, Lisha Chen, and Armand J. Fulco
}

Department of Biological Chemistry and the Laboratory of Structural Biology and Molecular Medicine, School of Medicine, University of California, Los Angeles, California 90024-1737

\begin{abstract}
We have developed an efficient method for site-directed mutagenesis using two subsequential rounds of PCR. In this method, PCR conditions are optimized to favor high fidelity of Taq DNA polymerase in the presence of equimolar concentrations of $\mathrm{MgCl}_{2}$ and $\mathrm{dNTP}$ in the reaction $\mathrm{mix}$ ture (pH 5.5-6.2). This method makes use of a pair of universal primers and the multiple cloning site of pUC/M13 vectors. Only one mutagenic primer is required per target site. In the second round of PCR, the $3^{\prime}$ extension of the wild-type DNA strand is blocked by the presence of a segment of nonhomologous sequence at its $3^{\prime}$ end, and as a consequence, the amplified, full-length DNA fragment is chiefly from the mutant strand. Furthermore, because the mutated DNA fragment has flanking restriction sites different from those of the wild-type DNA fragment, the wild-type DNA fragment is totally excluded in the step involving selective cloning of the mutant DNA fragment. This method was successfully used to introduce four, nonadjacent mutations in the $5^{\prime}$ regulatory region of the cytochrome $\mathrm{P450}_{\mathrm{BM}-3}$ gene. All 20 analyzed clones from these four cases of mutagenesis carried the desired mutations, and no undesired mutations were observed. We observed that the larger the number of mismatched nucleotide residues in the mutagenic primer, the higher the concentration of $\mathrm{MgCl}_{2}$ was necessary for successful PCR amplification. Our experimental results indicate that this method offers im-
\end{abstract}

provements in efficiency, flexibility, and fidelity.

P CR with Taq DNA polymerase has been widely used for both the amplification of specific DNA sequences and sitedirected mutagenesis. In the last 6 years, two major methods for site-directed mutagenesis using two subsequential rounds of PCR amplification have been developed. The first method, designated overlap extension, was described by Ho et al. ${ }^{(1)}$ In this method a pair of overlapping mutagenic primers and two flanking primers are required. With two different combinations of one flanking primer and one mutagenic primer, two DNA fragments having overlapping ends are generated by two separate PCR amplifications. These fragments are combined in a subsequent "fusion" reaction in which the overlapping ends anneal to each other, allowing the $3^{\prime}$ overlap of each strand to serve as a primer for the $3^{\prime}$ extension of the complementary strand. The resulting fusion product is amplified further by PCR. In practice, however, we found that the annealing of overlapping ends often fails to occur, which may be attributable to the complementary reassociation of double-stranded DNA in the fusion reaction and the adoption of secondary structure in single-stranded DNA produced in the subsequent PCR. The second method termed megaprimer, was developed by Landt et al., ${ }^{(2)}$ based on the scheme described by Kammann et al. ${ }^{(3)}$ This method requires just one mutagenic primer and two flanking universal primers for $\mathrm{pUC} / \mathrm{M} 13$ vectors. In the first round of PCR amplification, the mutagenic primer and the antiparallel universal primer are used to produce a specific DNA fragment carrying the mutation. This DNA fragment is purified and then used as a primer together with the second universal primer for the second round of PCR amplification. However, a frequent drawback of this method, as pointed out by Barettino et al., ${ }^{(4)}$ is inefficient priming by the megaprimer fragment in the second round of PCR amplification, which results in very low yields of the full-length fragment of target DNA. Recently, several different approaches for improving the megaprimer method have been described ${ }^{(4,5)}$ but, as the investigators, note, these approaches introduce their own limitations. Moreover, in reviewing the various procedures for PCR-mediated site-directed mutagenesis published to date, we found that little attention had been paid to the optimization of mutagenic PCR with regard to the fidelity of Taq DNA polymerase. Should DNA synthesis by Taq DNA polymerase, used for this purpose, be carried out under low-fidelity reaction conditions, the occurrence of undesired mutations would become a major concern.

On the basis of the megaprimer strategy, we developed an efficient method for site-directed mutagenesis using PCR for the introduction of multiple desired mutations in the $5^{\prime}$ regulatory region of the cytochrome $P 45 O_{B M-3}$ gene. There are three major advantages in the method that we present here. First, the extension of the $3^{\prime}$ end of wild-type DNA strand is blocked by the introduction of a segment of nonhomologous DNA sequence 
to its $3^{\prime}$ end so that the full-length fragment produced by the second round of PCR amplification is mainly from the $3^{\prime}$ extension of the mutant strand. Second, the mutated DNA fragment can be selectively cloned into a plasmid vector by using appropriate flanking restriction sites, as the mutated DNA fragment has flanking restriction sites different from those of the wild-type DNA fragment. Finally, the conditions of PCR for site-directed mutagenesis have been optimized with regard to fidelity of Taq DNA polymerase to minimize undesired mutations.

\section{MATERIALS AND METHODS}

\section{Materials}

Restriction endonucleases, T4 DNA ligase, and T4 DNA polymerase were purchased from either New England Biolabs or GIBCO BRL. Taq DNA polymerase was purchased from Promega. Oligonucleotide primers used in PCR and DNA sequencing were synthesized by Integrated DNA Technologies, Inc. Deoxynucleotide triphosphates (dNTPs) and $\left[\alpha{ }^{35}\right.$ S $]$ dATP were from Amersham Corp., the Geneclean kit was purchased from Bio 101, Inc., and the Sequenase kit and plasmid pTZ19R were from U.S. Biochemical Corp. The 5' regulatory region of the cytochrome $\mathrm{P} 45 \mathrm{O}_{\mathrm{BM}-3}$ gene in $\mathrm{Ba}$ cillus megaterium ATCC 14681 was cloned in our laboratory. ${ }^{(6)}$ The DNA sequence of the $\mathrm{P45O}_{\mathrm{BM}-3}$ gene, including the 5 ' regulatory region, is available under GenBank accession number J04832. Escherichia coli strain JM109 was used as a host for plasmid transformation and preparation. All chemicals used in the experiments were reagent grade or better.

\section{PCR}

The $5^{\prime}$ regulatory region $(1.63 \mathrm{~kb})$ of the cytochrome $P 450_{B M-3}$ gene was cloned into plasmid vector pTZ19R to yield a recombinant plasmid designated pFL3-1. To introduce site-directed mutations in the regulatory region, the first round of PCR was set up in a total volume of 100 $\mu l$ containing $1 \mu \mathrm{l}$ of pFL3-1 ( $\sim 5 \mathrm{ng}), 20$ pmoles of each primer, $10 \mu \mathrm{l}$ of $10 \times$ reaction buffer [500 mM KCl, $100 \mathrm{~mm}$ Tris$\mathrm{HCl}$ ( $\mathrm{pH} 9.0), 1.0 \%$ Triton X-100], and 2.5 units of Taq DNA polymerase; optimized amount of equimolar concentrations of $\mathrm{MgCl}_{2}$ and dNTP (see Optimization of Reaction Conditions for Mutagenic PCR, below) were added. The reaction mixtures were overlayed with $50 \mu \mathrm{l}$ of light mineral oil, and the reaction was carried out in an automatic thermal cycler for four cycles of $2 \mathrm{~min}$ at $94^{\circ} \mathrm{C}, 1 \mathrm{~min}$ at $48^{\circ} \mathrm{C}$, and $2 \mathrm{~min}$ at $72^{\circ} \mathrm{C}$, and then for 20 cycles of $1 \mathrm{~min}$ at $92^{\circ} \mathrm{C}$, $1 \mathrm{~min}$ at $58^{\circ} \mathrm{C}$, and $2 \mathrm{~min}$ at $72^{\circ} \mathrm{C}$. The $72^{\circ} \mathrm{C}$ incubation of the last cycle was extended for an extra $5 \mathrm{~min}$ before the reaction samples were cooled to room temperature. The second round of PCR amplification was set up as described previously, ${ }^{(7)}$ except $2 \mathrm{~mm} \mathrm{MgCl}_{2}$ and 0.5 mM each of the four dNTPs were used here. The PCR was performed for $20 \mathrm{cy}$ cles, each cycle consisting of $92^{\circ} \mathrm{C}$ for 1 $\min , 57^{\circ} \mathrm{C}$ for $1 \mathrm{~min}$, and $72^{\circ} \mathrm{C}$ for 2.5 $\min$. The last cycle was followed by $72^{\circ} \mathrm{C}$ for $5 \mathrm{~min}$ before cooling to room temperature.

\section{General DNA Methods}

DNA cloning, plasmid isolation, restriction enzyme digestion, and gel electrophoresis were performed according to current procedures. ${ }^{(8)}$ Recovery of DNA fragments from low-melt agarose gel with the Geneclean kit was carried out following the protocols supplied by the manufacturer. DNA sequencing analysis was performed by the dideoxy method ${ }^{(9)}$ using pUC/M13 universal primers and $P 450_{B M-3}$-specific synthetic primers.

\section{RESULTS}

Optimization of Reaction Conditions for Mutagenic PCR

Minimizing the frequency of undesired mutations in PCR-mediated site-directed mutagenesis can be achieved by maximizing the fidelity of the DNA polymerase. The error rate of Taq DNA polymerase used in the PCR can be influenced by many factors in the reaction; ${ }^{(10,11)}$ major factors include $\mathrm{MgCl}_{2}$ level, dNTP concentration, and $\mathrm{pH}$ conditions. Eckert and Kunkel ${ }^{(11)}$ evaluated these factors extensively in PCR and reported that high fidelity of Taq DNA polymerase could be reached when $\mathrm{MgCl}_{2}$ and dNTP were present at equimolar concentration or at a $\mathrm{pH}$ between 5 and $6\left(70^{\circ} \mathrm{C}\right)$ at $1.5 \mathrm{mM} \mathrm{MgCl}_{2}$. Because the PCR mixtures, when set up with the $10 \times$ reaction buffer supplied with Taq DNA polymerase from Promega, gave a $\mathrm{pH}$ of $5.5-6.2$ at $70^{\circ} \mathrm{C}$, our efforts to optimize the mutagenic PCR conditions with regard to the fidelity of Taq DNA polymerase were focused on the adjustment of the $\mathrm{MgCl}_{2}$ and dNTP concentrations. Mutagenic primers and pUC/M13 universal primers used for the introduction of mutations in three different locations of the $5^{\prime}$ regulatory region of the $P 450_{B M-3}$ gene are shown in Table 1 . The mutagenic primers carry one to nine mutant nucleotide residues. Because the error rate of DNA synthesis by Taq DNA polymerase in the PCR has been shown to increase with increasing $\mathrm{MgCl}_{2}$ concentration (dNTP at $1 \mathrm{mM}$ ), ${ }^{(11)}$ the minimum concentration of $\mathrm{MgCl}_{2}$ required for efficient mutagenic PCR amplification is the optimum level of $\mathrm{MgCl}_{2}$ in the reaction mixture for the purpose of minimizing undesired mutations. PCR was set up with 1-4.5 $\mathrm{mM} \mathrm{MgCl}_{2}$ for each pair of primers, with the results shown in Figure 1. In PCR with a pair of universal primers, forward primer (pUC/M13-F) and reverse primer (pUC/M13-R), the tar-

TABLE 1 Two Universal and Three Mutagenic Primers Used for Site-directed Mutagenesis by PCR in the 5'-Regulatory Region of the Cytochrome $\mathrm{P} 5 \mathrm{O}_{\mathrm{BM}-3}$ Gene of Bacillus megaterium

\begin{tabular}{|c|c|c|c|c|}
\hline Primer & Designation & Sequence & Mismatches (bp) & Product size (bp) \\
\hline 1 & pUC/M13-F & 5'-CGCCAGGGTTTTCCCAGTCACGAC-3' & 0 & \\
\hline \multirow[t]{4}{*}{2} & pUC/M13-R & 5'-TCACACGGAAACAGCTATGACC-3' & 0 & 1780 \\
\hline & $\mathrm{JV}_{\mathrm{m} 2}$ & 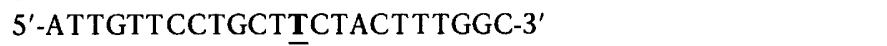 & 1 & 1163 \\
\hline & $\mathrm{BB}_{3 \mathrm{~m} 2}$ & 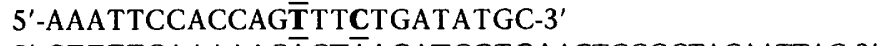 & 2 & 1418 \\
\hline & $\mathrm{O}_{\mathrm{IIIm} 2}$ & 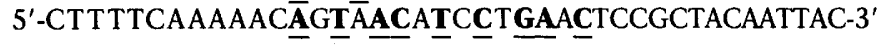 & 9 & 1025 \\
\hline
\end{tabular}




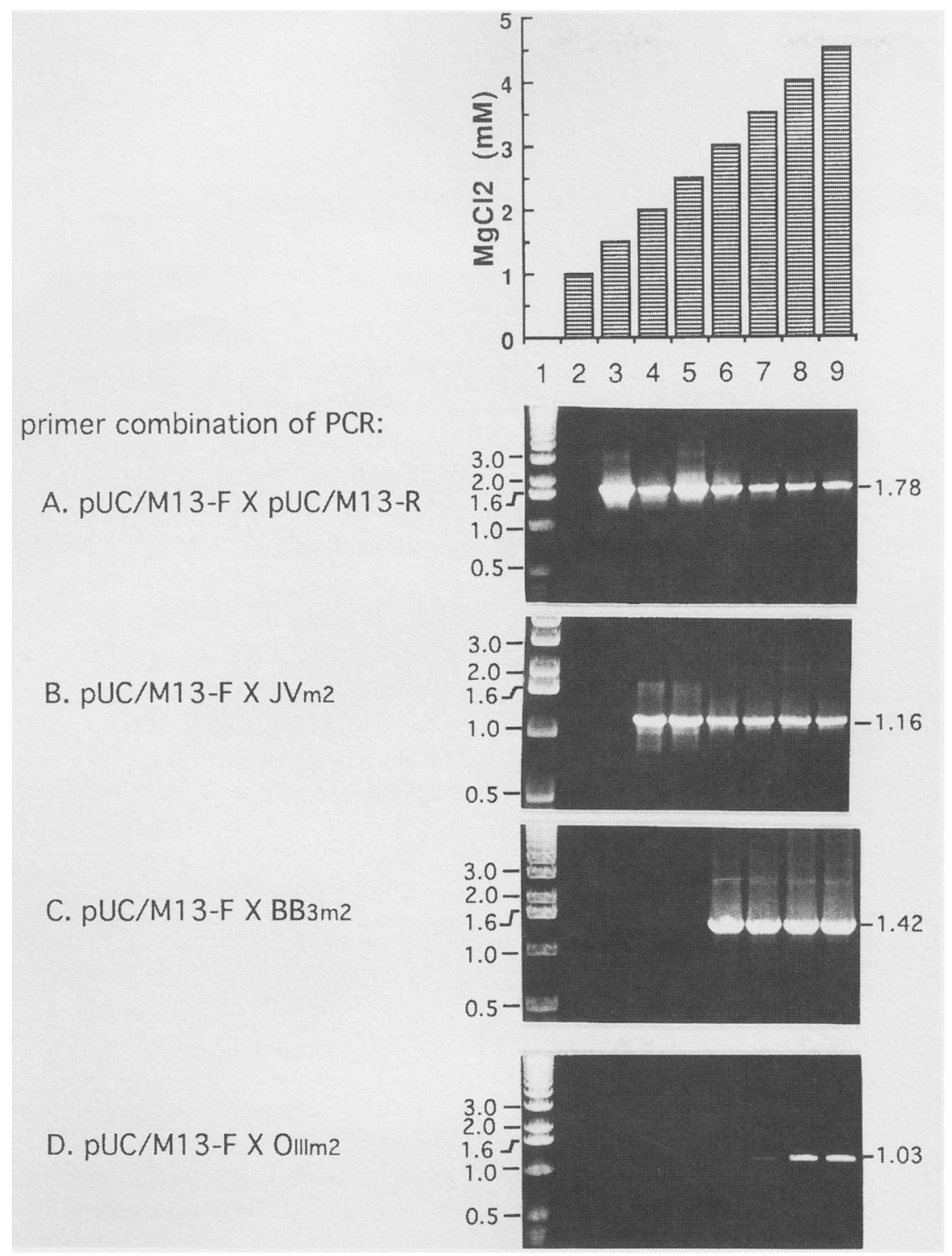

FIGURE 1 The minimal requirement of $\mathrm{MgCl}_{2}$ for each mutagenic PCR is determined by monitoring the PCR-amplified target DNA by electrophoresis on an agarose gel. Each primer combination and its corresponding amplified DNA fragment, as analyzed by agarose gel electrophoresis, are placed side by side. PCR samples on all four gels have the same lane alignments. For each PCR reaction (100 $\mu \mathrm{l}$ total), $10 \mu \mathrm{l}$ of sample was loaded onto the gel. (Lane 1) DNA molecular weight standards; (lanes 2-9) results of eight different PCR samples with a range of 1-4.5 mM $\mathrm{MgCl}_{2}$ in the reaction mixtures (see the plot, top). The sizes of the standards (left) and those of specific amplified DNA fragments (right) are shown on the sides of the electrophoretographs.

get DNA fragment $(1.78 \mathrm{~kb})$ was significantly amplified when the $\mathrm{MgCl}_{2}$ concentration was $>1.5 \mathrm{~mm}$. However, with mutagenic primers, the PCR amplification needed higher concentrations of $\mathrm{MgCl}_{2}$. For example, in the PCR with pUC/M13-F and mutagenic primer $\mathrm{JV}_{\mathrm{m} 2}$ (which carried one mismatched nucleotide), the minimal concentration of $\mathrm{MgCl}_{2}$ required for efficiency was $2 \mathrm{mM}$. For $\mathrm{pUC} / \mathrm{M} 13-\mathrm{F}$ and mutagenic primer $\mathrm{BB}_{3 \mathrm{~m} 2}$ (which contained two mis- matched nucleotides) specific PCR amplification was not observed until the $\mathrm{MgCl}_{2}$ in the reaction mixture reached a concentration of $3 \mathrm{~mm}$. For pUC/M13-F and mutagenic primer $\mathrm{O}_{\mathrm{IIIm} 2}$ (nine mismatched nucleotides), the minimal $\mathrm{MgCl}_{2}$ concentration for significant PCR amplification was $4 \mathrm{~mm}$. Thus, 2, 3, and 4 $\mathrm{mm} \mathrm{MgCl}_{2}$ were used as the optimal $\mathrm{MgCl}_{2}$ concentrations for the mutagenic PCR (the first round of PCR in the procedures as presented in the next section) with pUC/M13-F and mutagenic primer $\mathrm{JV}_{\mathrm{m} 2}, \mathrm{BB}_{3 \mathrm{~m} 2}$, and $\mathrm{O}_{\mathrm{IIIm} 2}$, respectively. The corresponding equimolar dNTP concentrations in the reactions for these three mutagenic PCR runs were $0.5,0.75$, and $1.0 \mathrm{~mm}$, respectively, of each of the four dNTPs (i.e., 2, 3, and $4 \mathrm{~mm}$ total).

\section{Procedures for Site-directed Mutagenesis Using PCR}

The strategy of the PCR method for sitedirected mutagenesis is outlined in Figure 2. The $\mathrm{P} 5 \mathrm{~B}_{\mathrm{BM}-3}$ promoter region of the 1.6-kb DNA fragment was cloned into pTZ19R through the unique SalI and $B a m H I$ sites at the multiple cloning site of the vector. The resulting construct contained multiple unique restriction sites at both flanking ends of the insert. The first round of PCR was mutagenic, using flanking primer pUC/M13-F and the mutagenic primer $\mathrm{m} 2$. The reaction was performed under the optimized conditions to favor the high fidelity of Taq DNA polymerase activity as described above. The specifically amplified DNA fragment was purified by low-melting agarose gel electrophoresis and the Geneclean kit. In the interim, the flanking restriction site " $\mathrm{A}$ " of the insert in the plasmid was replaced by restriction site "C" (HindIII in our examples) by DNA manipulation. In our experiments, the $K p n I$ site served as the A site. A 12-bp HindIII linker with the $5^{\prime}$ end phosphorylated was used as the $C$ site to replace the $K p n I$ site. Following $K p n I$ restriction enzyme digestion, the linearized plasmid was treated with $\mathrm{T}_{4}$ DNA polymerase in the presence of dNTP to generate blunt ends and then purified using Geneclean. Next, the linear plasmid was recircularized with the HindIII linker using DNA ligase. The resulting plasmid then was linearized by digestion with restriction enzyme $C$ and purified by using low-melting agarose gel electrophoresis (to remove undigested circular plasmid) and Geneclean. The linearized plasmid and the PCR-amplified DNA fragment containing the desired mutations $(-5 \mathrm{ng}$ for each preparation) were then combined and used as templates for the second round of PCR amplification. As shown in Figure 2, after the two DNA fragments were added together in the reaction mixture, the single-stranded DNA from the fragment of the first round of PCR (together with the identical single- 


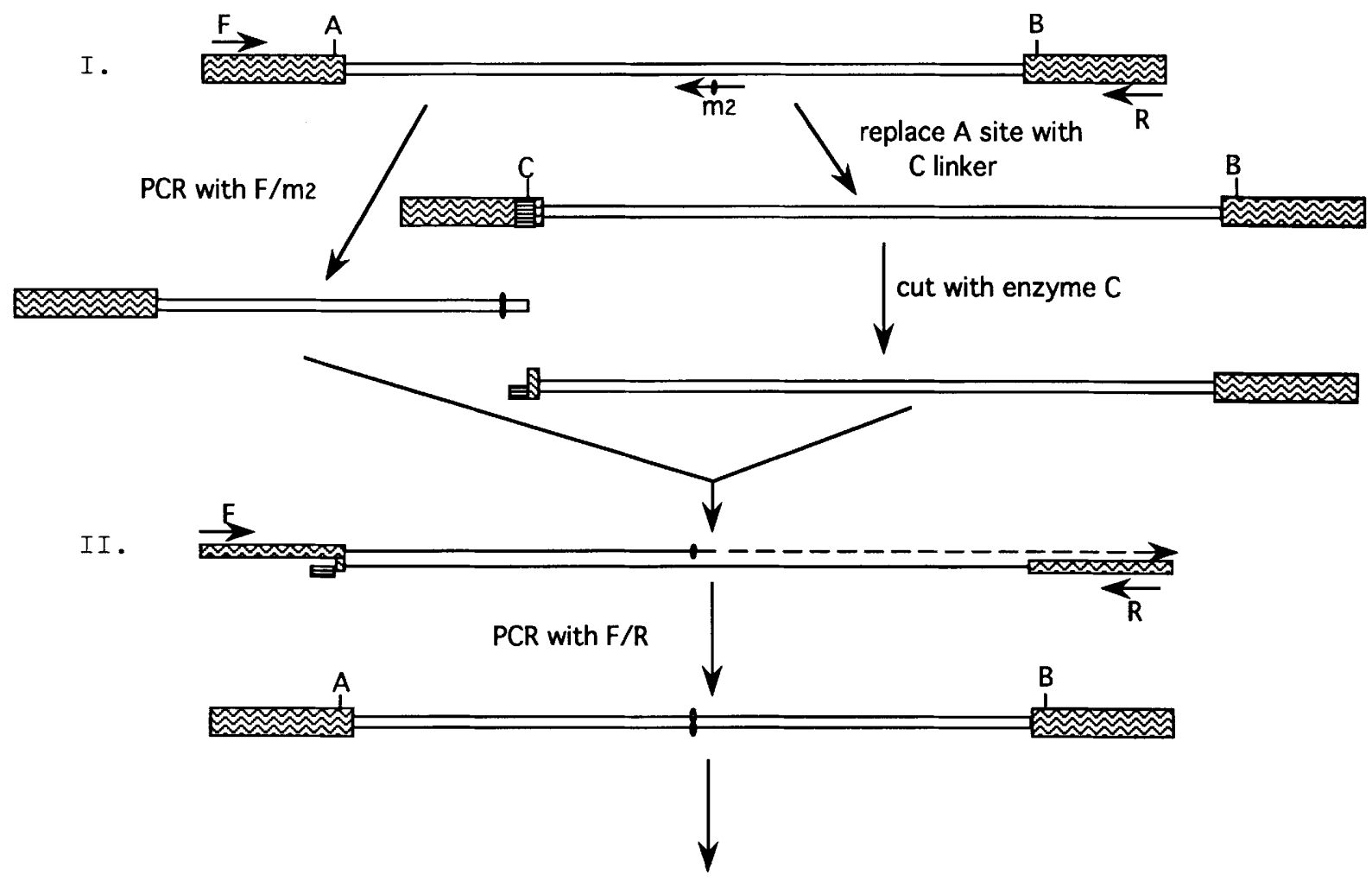

cut with restriction enzyme $A$ and $B$, cloning into plasmid vector.

FICURE 2 Diagrammatic scheme of the mutagenesis procedure. Only the insert (unfilled segment in diagram) and its flanking regions (shaded boxes) are shown here. $\mathrm{F}$ and $\mathrm{R}$ represent the pUC/M13 forward and reverse primers, respectively. The mutagenic primer is designated m2. A, B, and $\mathrm{C}$ represent three different flanking restriction sites. The $3^{\prime}$ extension is indicated by a broken line. $(I)$ The scheme for the first round of PCR (mutagenic); (II) the scheme for the second round of PCR.

stranded fragment from the first cycle of the second round of PCR as primed by pUC/M13-F) anneals to its complementary strand of the linearized plasmid DNA or to the single-stranded DNA generated by the pUC/M13-R primer in the PCR to form a heteroduplex. In this heteroduplex, the $3^{\prime}$ end of the mutant strand DNA could be extended to the pUC/M13-R primer annealing site to generate a full-length mutated singlestranded insert. This single-stranded DNA then became a homoduplex DNA in the second cycle of the PCR primed by pUC/M13-R primer. In contrast, the $3^{\prime}$ end of the wild-type strand DNA of the heteroduplex could not be extended because the $3^{\prime}$ end (4 nucleotide residues in our examples) was not homologous to its template and the Taq DNA polymerase, which lacks a $3^{\prime} \rightarrow 5^{\prime}$ exonuclease activity, was not capable of proofreading. ${ }^{(12)}$ The homoduplex DNA containing the desired mutation was amplified by the two flanking universal primers in the remaining cycles of the second round of PCR. The full-length in- sert carrying the desired mutation was then selected by digestion with restriction enzymes $A$ and $B$ and recovered by low-melting agarose gel electrophoresis and Geneclean treatment. The resulting mutated DNA fragment was cloned into vector pTZ19R by using the same $A$ and $B$ restriction sites. Because any wild-type DNA fragments that might, by chance, be amplified in the PCR would carry flanking restriction sites $B$ and $C$, they were excluded in the cloning step because the A and $B$ restriction sites were used for this process. Finally, the desired mutation in the insert may now be confirmed by DNA sequencing analysis.

\section{Mutagenesis of the $\mathbf{P 4 5 0}_{\mathrm{BM}-3}$ Promoter Region Using PCR}

Using PCR, we successfully introduced desired mutations into four different locations on the $5^{\prime}$ regulatory region of the $P 45 O_{B M-3}$ gene. Figure 3 shows the results of PCR with two different primer combinations for site-directed mutagenesis at the JV site. In the first case, the mutagenic PCR was carried out with mutagenic primer $\mathrm{JV}_{\mathrm{m} 1}$ and pUC/M13-R (Fig. 3 , lane 1 ). The flanking restriction site $B$ was replaced by $\mathrm{C}$ in the plasmid. After the combination of the mutated DNA fragment and the plasmid linearized by the digestion with restriction enzyme $C$, the full-length target DNA fragment containing the desired mutation was amplified successfully in the second round of PCR (Fig. 3, lane 3). In the second case, the first round of PCR was carried out with mutagenic primer $\mathrm{JV}_{\mathrm{m} 2}$ and $\mathrm{pUC} /$ M13-F (Fig. 3, lane 2). The flanking restriction site $A$ was replaced by $C$ in the plasmid, and the second round of PCR also significantly amplified the target DNA fragment (Fig. 3, lane 4). Our overall evaluation of these two alternative ways for introducing mutations at the JV site, and the successful use of these procedures for the introduction of four nonadjacent mutations into the $5^{\prime}$ regulatory region of the $P 450_{B M-3}$ gene, indicates that our PCR method is very flexible in practice. 


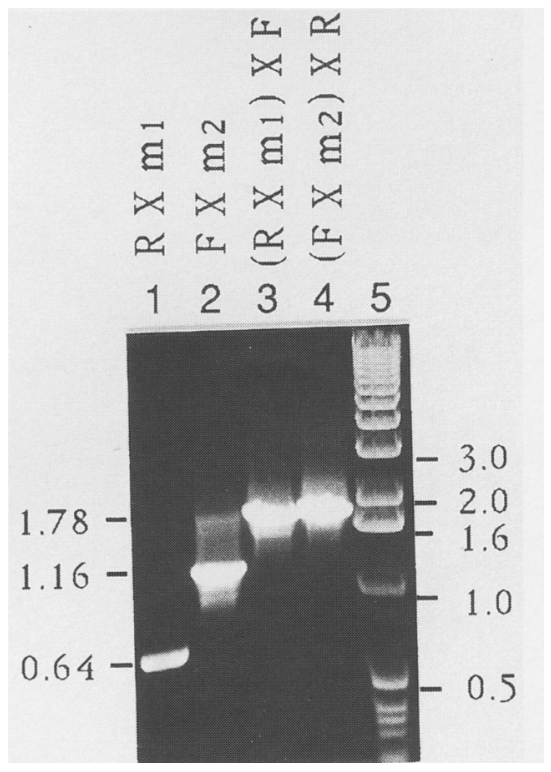

FIGURE 3 The PCR products of two alternative primer combinations for site-directed mutagenesis on the JV site of the 5 ' regulatory region of $P 45 O_{B M-3}$ are shown after agarose gel electrophoresis. Ten microliters of PCR sample was loaded in each lane. The amplified DNA products were visualized on the agarose gels by ethidium bromide staining. (Lane 1) $\mathrm{R} \times \mathrm{m} 1$ and (lane 3$)(\mathrm{R} \times \mathrm{m} 1) \times \mathrm{F}$ (lane 3 ) represent the first round and the second round of PCR with a primer combination of PUC/M13$\mathrm{R}$, and $\mathrm{JV}_{\mathrm{m} 1}$, respectively; (lane 2) $\mathrm{F} \times \mathrm{m} 2$ and (lane 4) $(\mathrm{F} \times \mathrm{m} 2) \times \mathrm{R}$ represent the first round and the second round of PCR with a primer combination of $\mathrm{pUC} / \mathrm{M} 13-\mathrm{F}$ and $\mathrm{JV}_{\mathrm{m} 2}$ respectively. The sizes of the standards (right) and those of specific-amplified DNA fragments (left) are shown at each side.

For each of these four cases of mutagenesis, five clones were picked randomly for DNA sequence analysis. The results showed that all of the analyzed clones (20 total) had the desired mutations. For each of the analyzed clones, $\sim 200 \mathrm{bp}$ around the mutation site was checked and no undesired mutation was observed. In another experiment, the full length $(1.63 \mathrm{~kb})$ of the 5 ' regulatory region of $P 45 O_{B M-3}$ gene containing multiple mutations on three different locations was checked by DNA sequencing analysis. Again, no undesired mutation was observed. These results indicate that our PCR method introduces mutations very efficiently and with high fidelity.

\section{DISCUSSION}

The PCR method that we have described here has been used successfully in our laboratory for site-directed mutagenesis on the $5^{\prime}$ regulatory region of the cytochrome $P 45 O_{B M-3}$ gene in $B$. megaterium. Our PCR method offers improvements over other PCR mutagenesis techniques in efficiency, flexibility, and fidelity.

In this method wild-type parental DNA is prevented from extension at the 3 ' end (Fig. 2) and is thus essentially excluded from amplification during the second round of PCR. Moreover, the mutant DNA fragment generated by the second round of PCR amplification has flanking restriction sites different from those of the wild-type parental DNA fragment; this allows for the selective cloning of the mutant DNA fragment and, hence, exclusion of the wild-type DNA fragment in the subsequent cloning step. When we compared this method with the megaprimer and overlap extension methods for the introduction of site-directed mutations at four different locations on the $5^{\prime}$ regulatory region of the $P 45 O_{B M-3}$ gene, our procedure proved superior. For example, for mutagenesis at the $\mathrm{O}_{11 \mathrm{I}}$ site using the megaprimer method, a very low yield in the second round of PCR amplification was obtained and only one of eight clones analyzed carried the desired mutation. With the overlap extension method, only the desired mutations at the $\mathrm{BB}_{3}$ site were amplified in the second round of PCR; the other three cases of mutagenesis were unsuccessful.

The basic strategy employed in our method involves the use of a pair of universal primers, pUC/M13 forward (F) and reverse $(R)$ primers, which flank the inserts in the pUC/M13 vectors. Only one mutagenic primer is required per target site. As a consequence, this method, as demonstrated by our experiments presented here, is suitable for introducing multiple, nonadjacent mutations subsequentially on the same DNA molecule with high efficiency. Furthermore, primer combinations can be changed at a mutation target site (Fig. 3), a flexibility in methodology that is especially important in cases where a specific primer pair fails to work in PCR for undetermined reasons, as has been reported. ${ }^{(13)}$

Our method also has the virtue of high fidelity, as indicated by our mutagenesis results. In the introduction of four, nonadjacent mutations into the $5^{\prime}$ regulatory region of the $P 450_{B M-3}$ gene using our method, no undesired mutations were observed among the analyzed clones. In practice, high fidelity is very important as researchers, after performing site-directed mutagenesis on a coding sequence or a regulatory region using PCR, usually check only 200-300 bp of sequence around the mutation site rather than the whole length of inserted DNA. If there is an undesired mutation associated with the desired mutation on the same DNA molecule, the effects of the desired mutation could be influenced or even completely altered by the undesired mutation. Some investigators $^{(14)}$ have suggested using Vent DNA polymerase instead of Taq DNA polymerase for site-directed mutagenesis using PCR, as the fidelity of Vent DNA polymerase is 5 - to 10 -fold higher than that observed for Taq DNA polymerase. ${ }^{(15)}$ However, the $3^{\prime} \rightarrow 5^{\prime}$ proofreading exonuclease activity of Vent DNA polymerase may remove the mismatched nucleotide residues of the mutagenic primer and lead to a dramatically decreased mutation efficiency. For example, if used in our PCR method, the $3^{\prime} \rightarrow 5^{\prime}$ proofreading activity of Vent DNA polymerase would remove the $3^{\prime}$ nonhomologous sequence of the wildtype DNA strand in the heteroduplex and lead to amplification of parental DNA. An alternative approach would employ Vent $\left(\mathrm{Exo}^{-}\right.$) DNA polymerase (New England Biolabs), which has been genetically engineered to eliminate the $3^{\prime} \rightarrow 5^{\prime}$ proofreading exonuclease activity. ${ }^{(16)}$ However, because the fidelity of Vent $\left(\mathrm{Exo}^{-}\right)$DNA polymerase is only twofold higher than that of Taq DNA polymerase, ${ }^{(15)}$ we would still recommend optimization of the reaction conditions to maximize the fidelity of Vent $\left(\mathrm{ExO}^{-}\right)$DNA polymerase in PCR for sitedirected mutagenesis. With respect to optimization, the reason for the requirement of higher concentrations of $\mathrm{MgCl}_{2}$ for PCR amplification with primers containing multiple mismatched nucleotide residues (Fig. 1) is not clear. It seems likely, however, that the mutagenic primer/template hybrids need the presence of higher of $\mathrm{Mg}^{++}$concentrations to maintain their stability at high annealing temperatures.

It should also be noted that Taq DNA polymerase has been reported to catalyze the untemplated addition of an $\mathrm{A}$ (deoxyadenosine) residue at the $3^{\prime}$ end of the amplified DNA fragment. ${ }^{(17,18)}$ 
Mutagenic primers should therefore be designed as described ${ }^{(19)}$ so that the first 5 ' nucleotide of a mutagenic primer follows a $\mathrm{T}$ residue in the same strand of template sequence. The amplified DNA fragment from the first round of $P C R$ will thus have the correct sequence. When a $\mathrm{T}$ residue is not available before the first $5^{\prime}$ nucleotide of a mutagenic primer, the DNA fragment amplified by the first round of PCR must be treated with $\mathrm{T}_{4}$ DNA polymerase to remove the additional $3^{\prime}$ residue before carrying out the second round of PCR amplification.

\section{ACKNOWLEDGMENTS}

We thank Keynes Tong from this laboratory for his excellent technical assistance in several of the experiments reported here. The research reported in this paper was supported by National Institutes of Health Research grant GM23913 and by the Director of the Office of Energy Research, Office of Health and Environmental Research, contract DE-FC03ER06015.

\section{REFERENCES}

1. Ho, S.N., H.D. Hunt, R.M. Horton, J.K. Pullen, and L.R. Pease. 1989. Site-directed mutagenesis by overlap extension using the polymerase chain reaction. Gene 77: 51-59.

2. Landt, O., H.P. Grunert, and U. Hahn. 1990. A general method for rapid site-directed mutagenesis using the polymerase chain reaction. Gene 96: 125-128.

3. Kammann, M., J. Laufs, J. Schell, and B. Gronenborn. 1989. Rapid insertional mutagenesis of DNA by polymerase chain reaction (PCR). Nucleic Acids Res. 17: 5404.

4. Barettino, D., M. Feigenbutz, R. Valcarcel, and H.G. Stunnenberg. 1994. Improved method for PCR-mediated site-directed mutagenesis. Nucleic Acids Res. 22: 541542.

5. Marini, F. III, A. Naeem, and J.N. Lapeyre. 1993. An efficient 1-tube PCR method for internal site-directed mutagenesis of large amplified molecules. Nucleic Acids Res. 21: 2277-2278.

6. Ruettinger, R.T., L.-P. Wen, and A.J. Fulco. 1989. Coding nucleotide, $5^{\prime}$ regulatory, and deduced amino acid sequences of $\mathrm{P}^{4} 50_{\mathrm{BM}-3}$, a single peptide cytochrome P450:NADPH-P450 reductase from Bacillus megaterium. J. Biol. Chem. 264: 1098710995.

7. Liang, Q. and T. Richardson. 1992. A simple and rapid method for screening transformant yeast colonies using PCR. BioTechniques 13: 730-735.
8. Sambrook, J., E.F. Fritsch, and T. Maniatis, eds. 1989. Molecular cloning: A laboratory manual. Cold Spring Harbor Laboratory Press, Cold Spring Harbor, New York.

9. Sanger, F., S. Nicklen, and A.R. Coulson. 1977. DNA sequencing with chain-terminating inhibitors. Proc. Natl. Acad. Sci. 74: 5463-5467.

10. Ling, L.L., P. Keohavong, Dias, C., and W.G. Thilly. 1991. Optimization of the polymerase chain reaction with regard to fidelity: Modified T7, Taq, and Vent DNA polymerase. PCR Methods Applic. 1: 63-69.

11. Eckert, K.A. and T.A. Kunkel. 1990. High fidelity DNA synthesis by the Thermus aquaticus DNA polymerase. Nucleic Acids Res. 18: 739-3744.

12. Tindall, K.R. and T.A. Kunkel. 1988. Fidelity of DNA synthesis by the Thermus aquaticus DNA polymerase. Biochemistry 27: 6008-6013.

13. Saiki, R.K. 1989. The design and optimization of the PCR. In PCR technology (ed. H.A. Erlich), pp. 7-16. Stockton Press, New York.

14. Watkins, B.A., A.E. Davis, F. Cocchi, and M.S. Reitz Jr. 1993. A rapid method for site-specific mutagenesis using larger plasmids as templates. BioTechniques 15: 700-704.

15. Mattila, P., J. Korpela, T. Tenkanen, and K. Pitkanen. Fidelity of DNA synthesis by the Thermococcus litoralis DNA polymerase-an extremely heat stable enzyme with proofreading activity. Nucleic Acids Res. 19: 4967-4973.

16. Kong, H., R.B. Kucera, and W.E. Jack. 1993. Characterization of a DNA polymerase from the hyperthermophile archaea Thermococcus litoralis. Vent DNA polymerase, steady state kinetics, thermal stability, processivity, strand displacement, and exonuclease activities. J. Biol. Chem. 268: 1965-1975.

17. Clark, J.M. 1988. Novel non-templated nucleotide addition reactions catalyzed by procaryotic and eucaryotic DNA polymerase. Nucleic Acids Res. 16: 9677-9686.

18. Mole, S.E., R.D. Iggo, and D.P. Lane. 1989. Using the polymerase chain reaction to modify expression plasmids for epitope mapping. Nucleic Acids Res. 17: 3319.

19. Kuipers, O.P., H.J. Boot, and W.M. de Vos. 1991. Improved site-directed mutagenesis method using PCR. Nucleic Acids Res. 19: 4558 .

Received October 11, 1994; accepted in revised form January 6, 1995. 


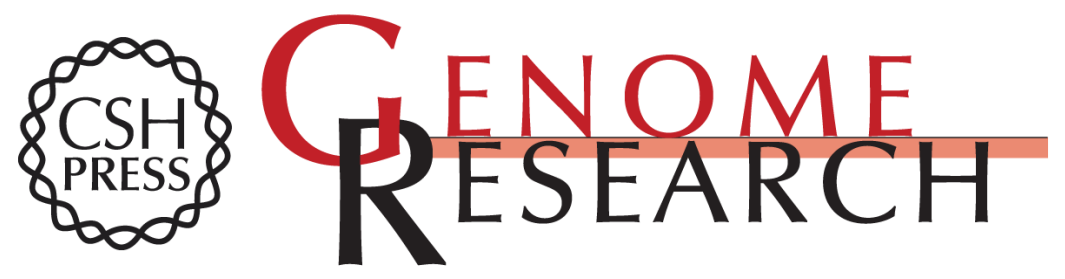

\section{An efficient and optimized PCR method with high fidelity for site-directed mutagenesis.}

$Q$ Liang, $L$ Chen and A J Fulco

Genome Res. 1995 4: 269-274

References This article cites 16 articles, 3 of which can be accessed free at: http://genome.cshlp.org/content/4/5/269.full.html\#ref-list-1

License

Email Alerting

Receive free email alerts when new articles cite this article - sign up in the box at the Service top right corner of the article or click here.

\section{Affordable, Accurate Sequencing.}

To subscribe to Genome Research go to: https://genome.cshlp.org/subscriptions 